http://jmscr.igmpublication.org/home/

ISSN (e)-2347-176x ISSN (p) 2455-0450

crossref DOI: https://dx.doi.org/10.18535/jmscr/v9i6.32

Journal Of Medical Science And Clinical Research

\title{
A Rare Case Report on Lipodystrophy of Perinodal Adipose Tissue Mimicking Metatstatic Signet Ring Cell Adenocarcinoma in a Cachexic Patient
}

\author{
Authors \\ Dr Abhilash Singh, Third Year Resident, Dr Anchana Gulati, Associate Professor \\ Corresponding Author \\ Dr Anchana Gulati, Associate Professor
}

\begin{abstract}
Cachexia is a complex syndrome and a comorbid condition commonly associated with a variety of chronic diseases like cancer, congestive heart failure, chronic obstructive pulmonary disease, chronic kidney disease and AIDS cancer. It results from metabolic dysregulation and is characterized by profound loss of adipose tissue and skeletal muscles. Approximately $20 \%$ of deaths in cancer patients are due to cachexia. Adipose tissue after undergoing cachectic dystrophy may mimics signet ring cell morphology histologically. Such lipodystrophied adipocytes mimicking signet ring cells are a diagnostic pitfall. We present a case of 54 years old male presenting with complains of pain upper abdomen for 1.5 years along with dysphagia and vomiting for last 4-5 months, diagnosed as moderately differentiated adenocarcinoma, biopsy pyloric stricture with metastatic tumor deposits in omental lymph node and lipodystrophy of adipocytes in the perinodal tissue.
\end{abstract}

\section{Case History}

54 years old male resident of Himachal Pradesh presented with complains of pain upper abdomen for 1.5 years along with dysphagia and vomiting for last 4-5 months in the surgery OPD.

\section{On Examination}

Patient had cachexia along with pallor. Per abdomen findings included tenderness on deep palpation in the epigastric region.

\section{Investigations}

CT abdomen was performed which was suggestive of gastric outlet obstruction caused by stricture at the pyloric antrum due to peptic ulcer disease. An endoscopy done three days later revealed an ulcer along with stricturous narrowing of the pyloric antrum.

\section{Biopsy}

In view of chronic gastric ulcer disease vagotomy was performed and surgical specimens were sent for HPE which included omental lymph nodes, common hepatic lymph nodes, part of omentum, anterior and posterior vagus and biopsy from the stricture, pylorus.

\section{Microscopic Examination}

Biopsy pylorus revealed denuded muscosal epithelium along with surface fibrinopurulent exudate and an invasive malignant tumor arranged as variably sized and shaped glands, nests and 


\section{JMSCR Vol||09||Issue||06||Page 165-172||June}

cords. One of the omental lymph node revealed metastatic moderately differentiated adenocarcinoma arranged in glands, nests trabecule and cords. Perinodal tissue showed discrete small sized adipocytes with slight variations in size and shape mimicking signet ring cells.

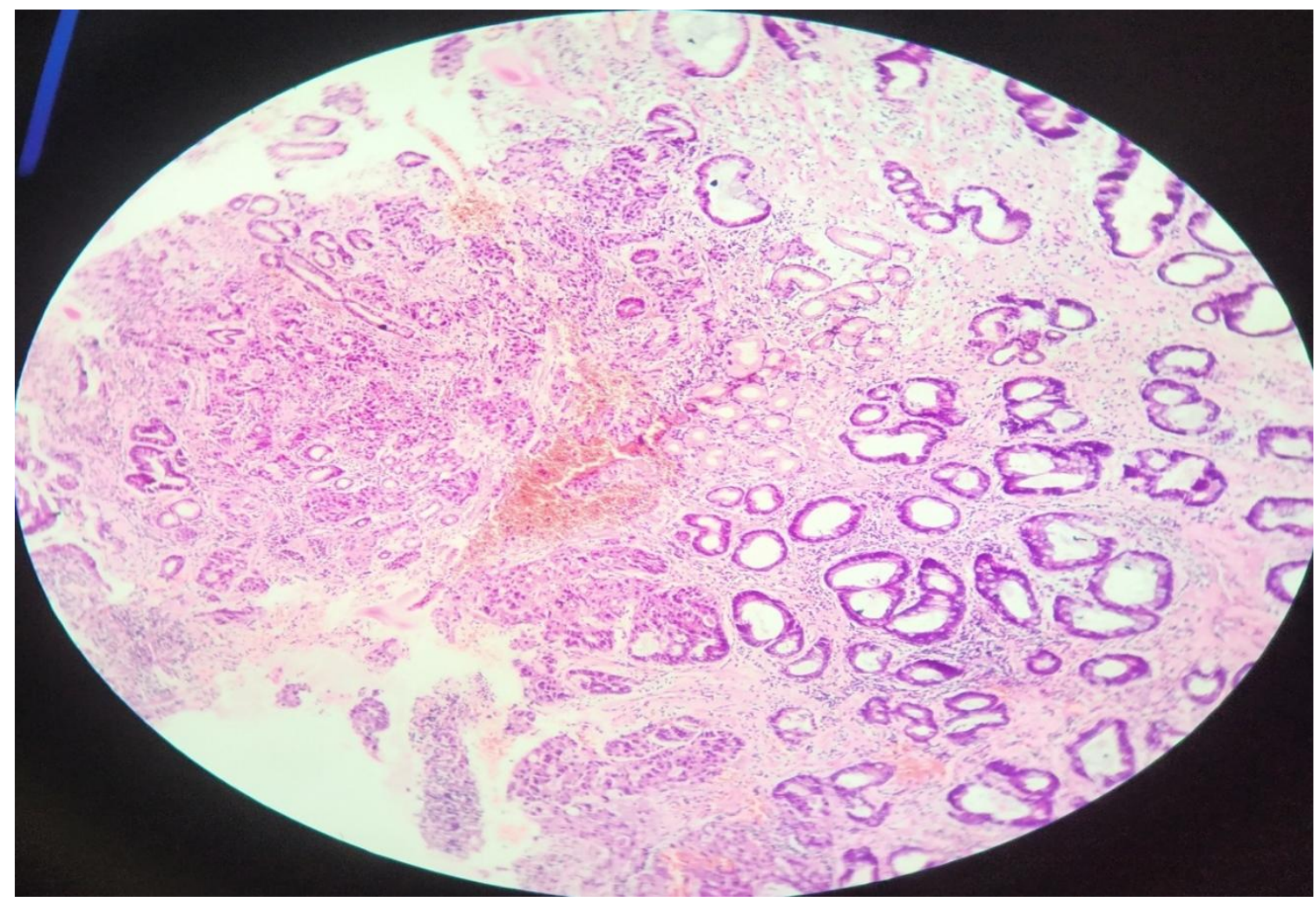

Invasive tumor arranged as variably sized and shaped glands nests and cords. 40X MAGNIFICATION

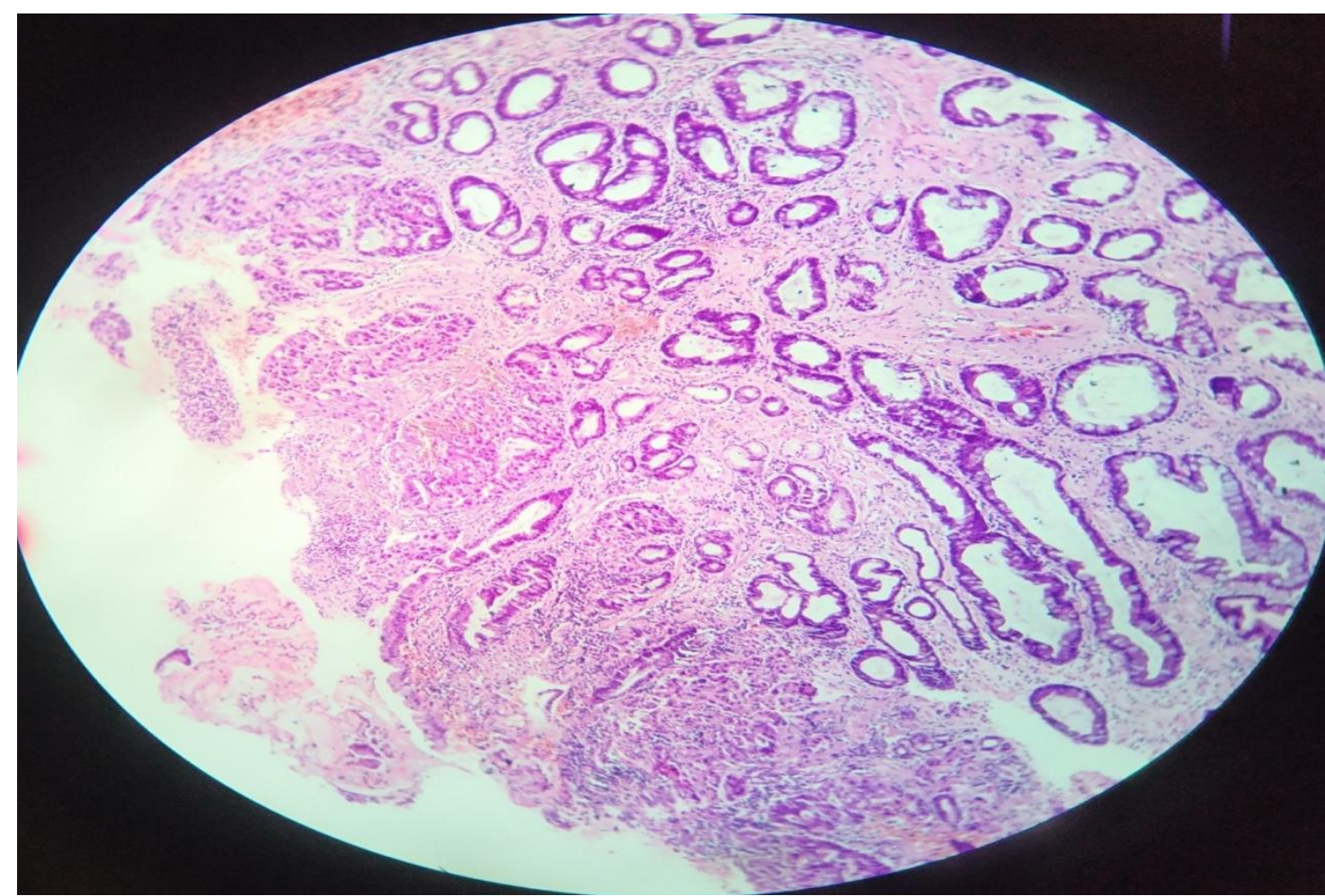

100X MAGNIFICATION 


\section{JMSCR Vol||09||Issue ||06||Page 165-172||June}

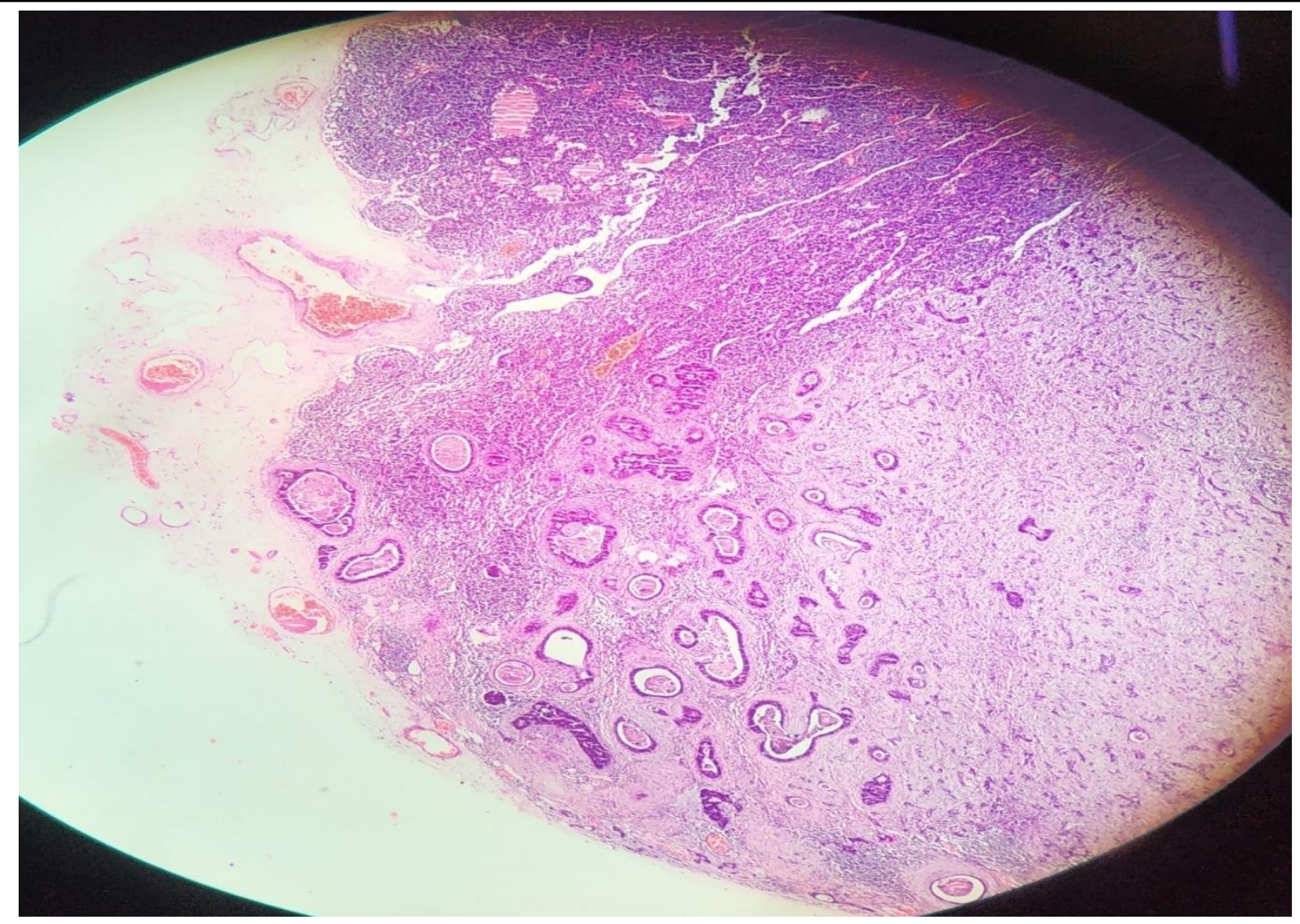

Omental lymph node revealing metastatic moderately differentiated adenocarcinoma. 40X MAGNIFICATION

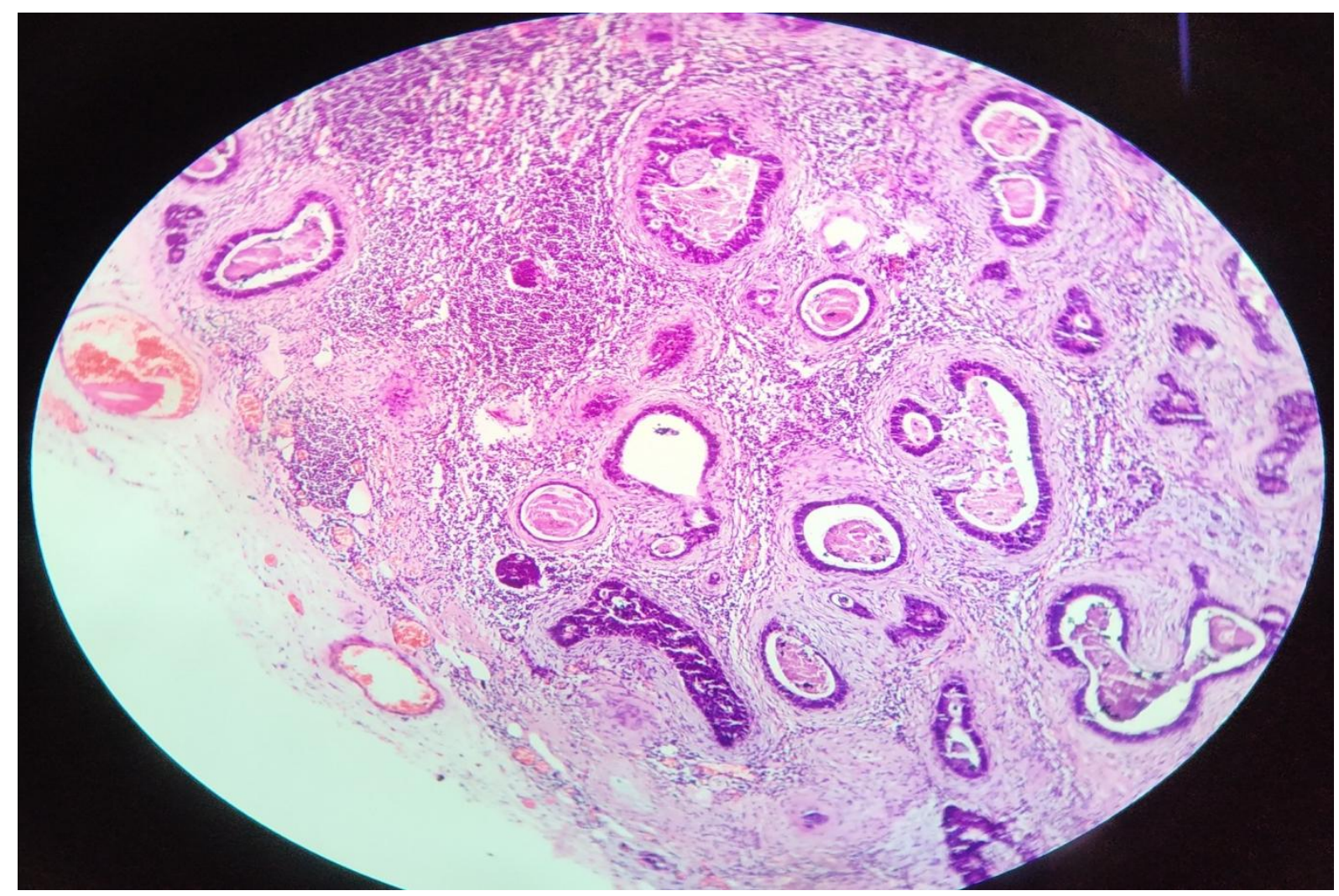

$100 \mathrm{X}$ MAGNIFICATION 


\section{JMSCR Vol||09||Issue||06||Page 165-172||June}

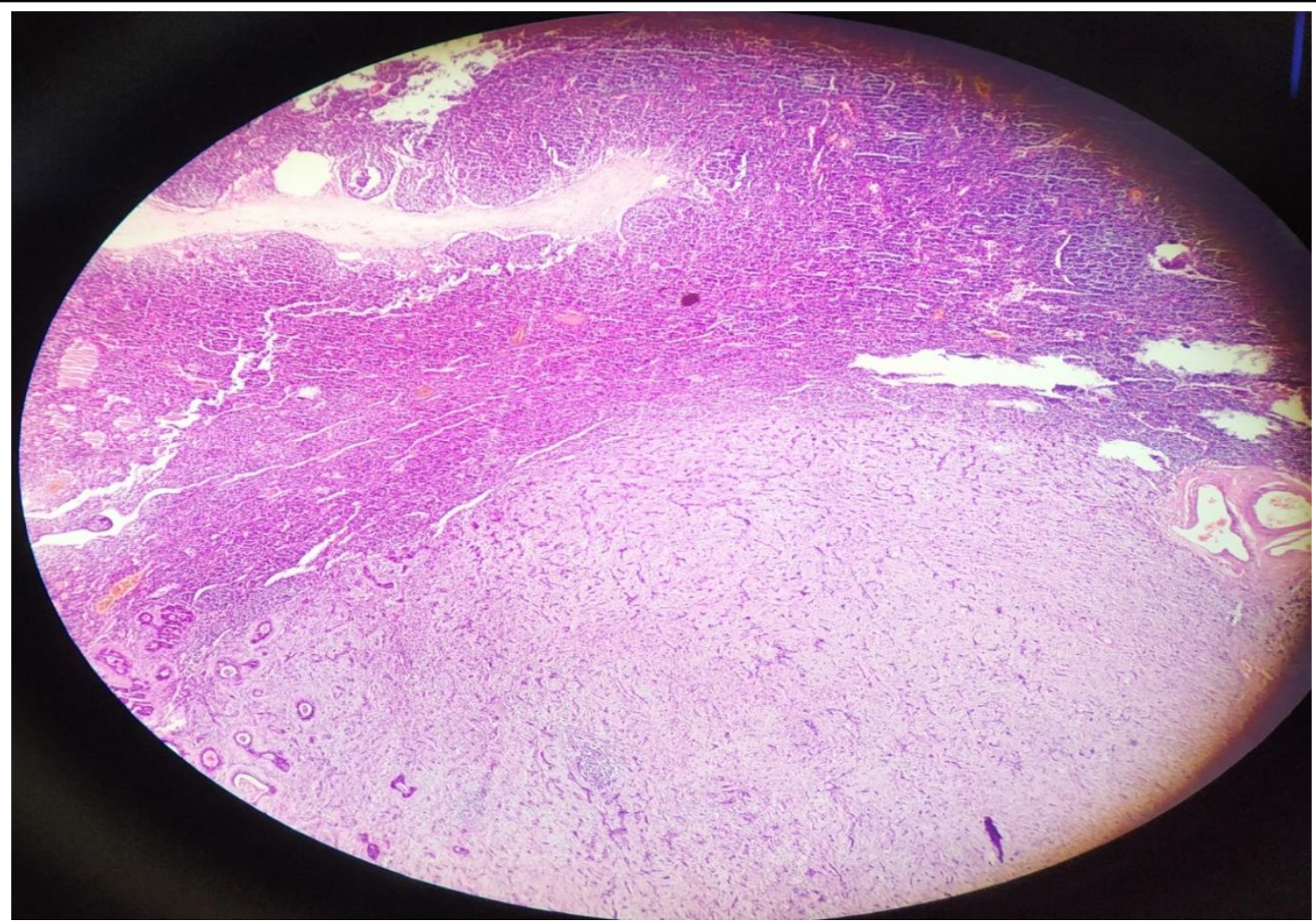

Lymph node involvement by tumors mainly in cords and trabeculae. 40X MAGNIFICATION

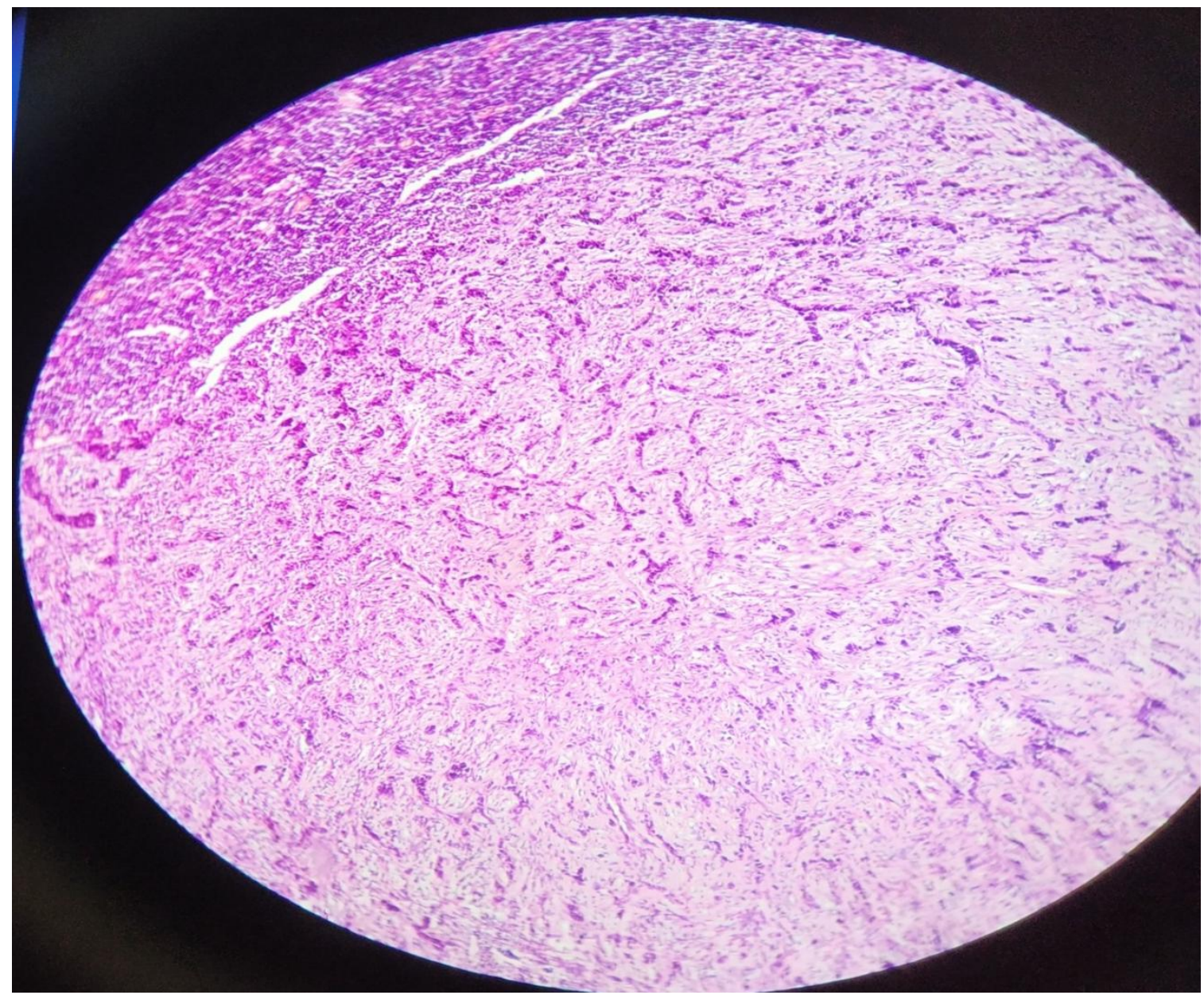

100 X MAGNIFICATION 


\section{JMSCR VoI||09||Issue||06||Page 165-172||June}

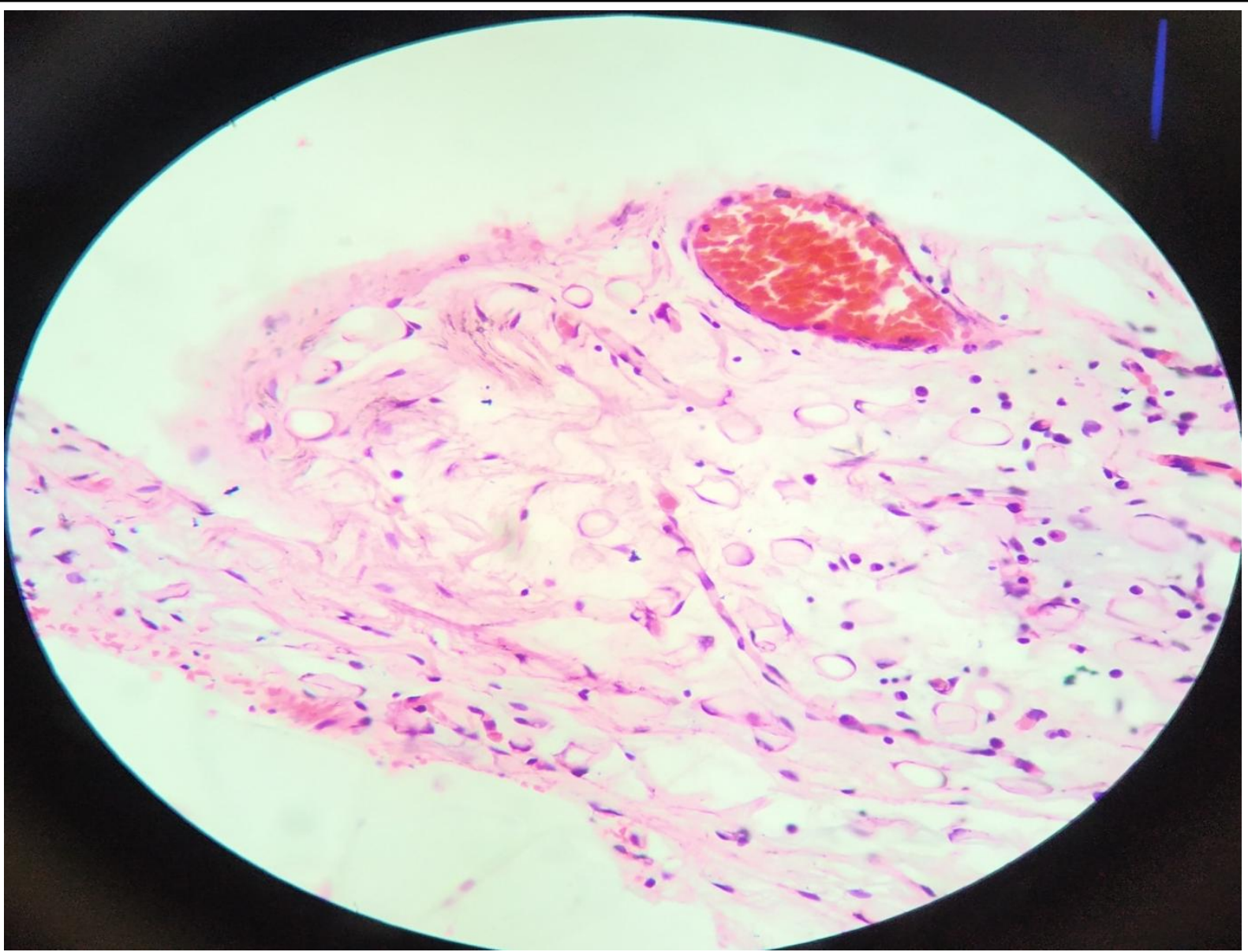

Discrete small sized adipocytes showing slight variations in size and shape. 'Mimicking signet ring cells.'

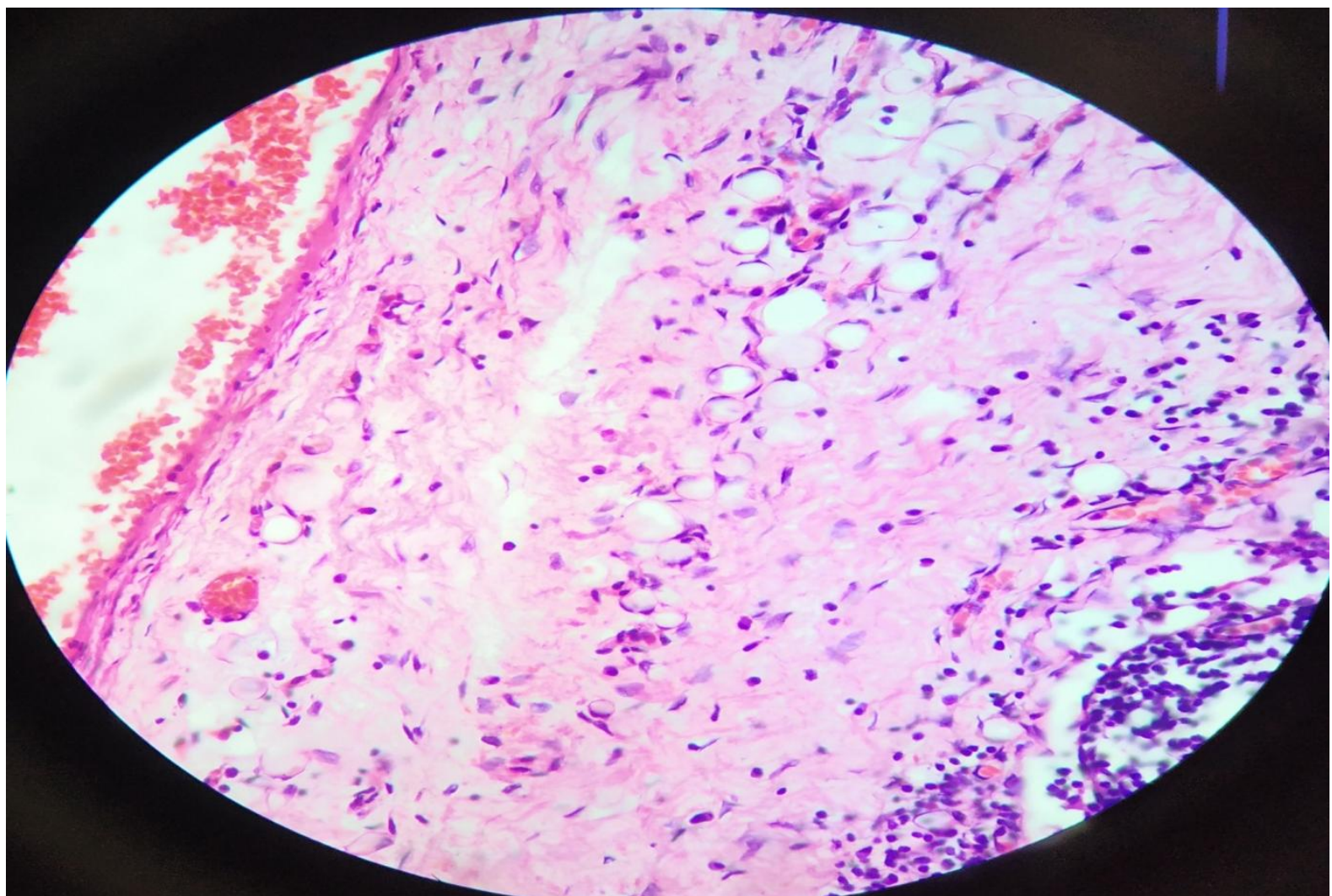

Another focus showing dytrophic adipocytes 


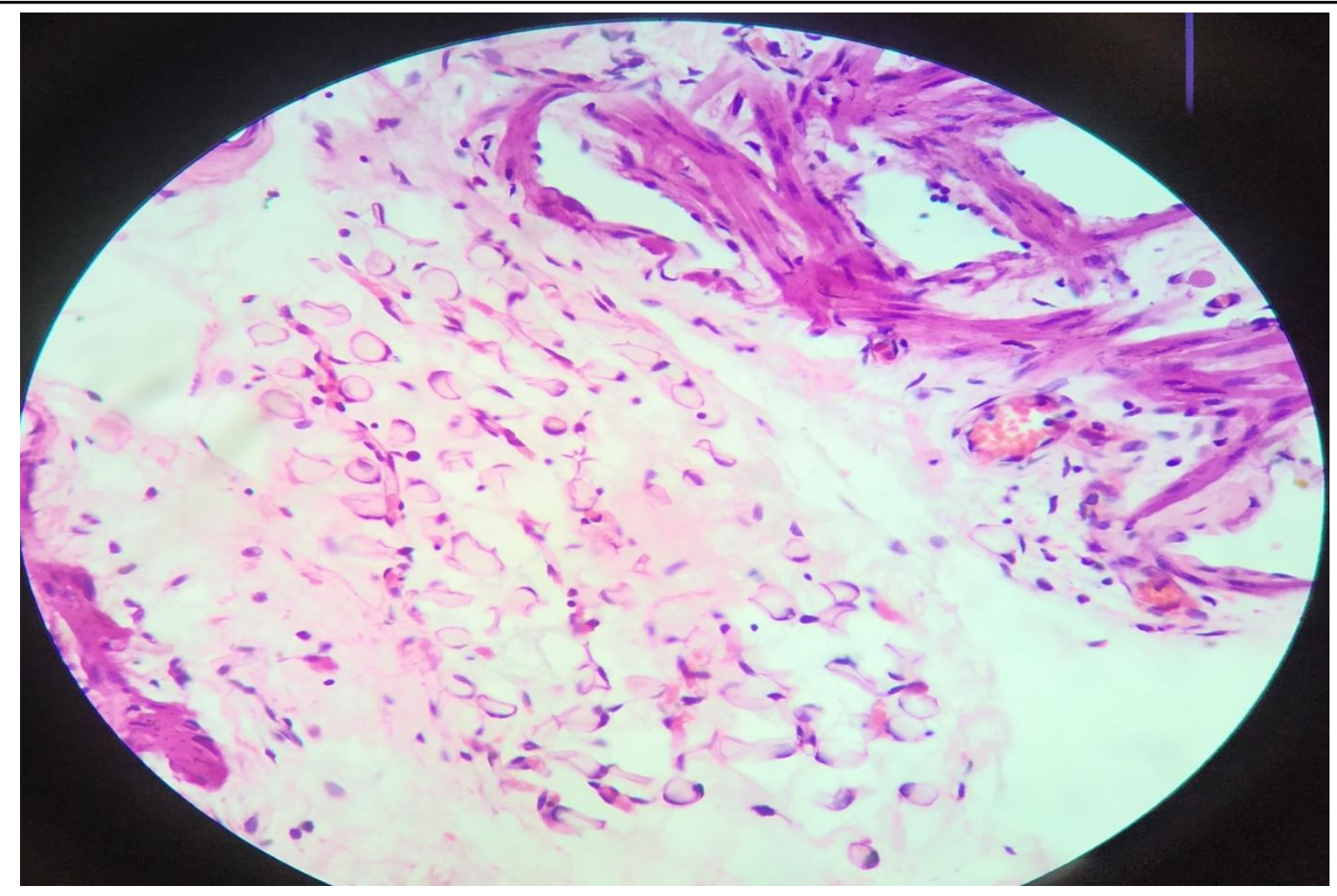

Another focus showing dystrophic adipocytes

\section{Discussion}

Cachexia is a debilitating condition and complex syndrome commonly associated with a variety of chronic diseases like cancer. It is caused by metabolic dysregulation and characterized by profound loss of adipose tissue and skeletal muscles ${ }^{13}$.Approximately $20 \%$ of deaths in cancer patients are due to cachexia ${ }^{1}$. Prolonged starvation, malnutrition and changes in metabolic processes cause tissues to undergo atrophy. The exact molecular and cellular mechanisms underlying the histological changes of adipose tissue atrophy are not fully understood. Studies have suggested that it results from the combination of increased metabolic processes and impaired anabolic function ${ }^{2,3}$.

Even though tissue atrophy occurs, the morphology of dystrophic organs and cells is usually still recognizable histologically. The remodeling of adipose tissue causes adipocytes to decrease in size, with increased size variation and a more rounded shape. The atrophic adipose tissue generally maintains a lobulated structure without infiltration and the dystrophic cells are separated by myxoid or mucoidstroma with fibrosis and a delicate vascular network ${ }^{13}$.

A variety of benign conditions and malignant neoplasms beyond signet ring cell adenocarcinoma have now been reported with signet ring-like cells. Non neoplastic lesions include gastric xanthomas, ${ }^{4}$ transurethral prostatectomy specimen $^{5}$, pseudomembranous colitis $^{6}$, signet ring-like cellular changes in gastrointestinal tract epithelial cells that are adjacent to ischemic or injured areas ${ }^{13}$. Few other reported cases include Signet ring-like cellular changes in muciphages ${ }^{7}$. Pena et al. reported a case of mucophagocytizing histiocytes in a low grade appendiceal mucinous neoplasm mimicking signet ring cell mucosecreting adenocarcinoma ${ }^{11}$, two cases involving subserosal adipocytes one being associated with chronic ischemic enteritis ${ }^{9}$ and the other in the setting of clostridium difficile colitis ${ }^{6}$ and two cases of starvation-induced fat atrophy involving the omentum ${ }^{10}$. Neoplastic lesions include schwannomas ${ }^{8}$, Lortscher et al. reported two cases of primary cutaneous 
squamous cell carcinoma and basal cell carcinoma showing signet ring cell-like morphology ${ }^{12}$.

Zhang et al. in 2018 examined a case of a cachetic patient with widespread atrophy and signet ring-like cellular morphology of adipose tissues, raising the differential diagnosis of metastatic signet ring cell carcinoma. They reported a case of this cachectic patient with pancreatic adenocarcinoma whose adipocytes underwent dramatic lipodystrophy mimicking signet ring cell adenocarcinoma ${ }^{13}$.

There are hypotheses that this signet ring change in lipocytes may be caused by cytoplasmic accumulation of various substances, cell degeneration with cytoplasmic vacuole formation, cytoplasmic membrane invagination, endoplasmic reticulum dilatations or processing $\operatorname{artifact}^{12}$.

Other identified factors responsible for lipodystrophy include reductions in mRNA levels of adipogenic transcription factors, their transcription products, and the enzymes and molecules involved in adipose tissue formation. $\mathrm{TNF} \alpha$ is also linked with increased lipolysis. Zinc- $\alpha 2$ - glycoprotein (ZAG), a novel adipokine, which is upregulated in cancer cachexia also promotes lipid breakdown ${ }^{14}$. In addition increased adiponectin, liver-derived CRP and plasma IL-6 levels also have been suggested to have a significant correlation with the presence of cachexia and cancer ${ }^{15,16,17 .}$.

\section{Conclusion}

Lipodystrophied adipocytes mimicking signet ring cells are diagnostic pitfall. Before signing out signet ring type adenocarcinoma one should always keep in mind the cachexic state of patient. More over other mimickers of signet ring cell morphology should always be considered in such situations as signet ring cells do not always reflect malignancy. Also in such cases immunoreactivity for S 100 could help arriving at the right diagnosis.

\section{References}

1. M. J. Tisdale, "Cachexia in cancer patients," Nature Reviews Cancer, vol. 2, no. 11, pp. 862-871, 2002.

2. T. Agustsson, M. Ryd'en, J. Hoffstedt et al., "Mechanism of increased lipolysis in cancer cachexia," Cancer Research, vol. 67, no. 11, pp. 5531-5537, 2007.

3. C. Bing and P. Trayhurn, "New insights into adipose tissue atrophy in cancer cachexia," Proceedings of the Nutrition Society, vol. 68, no. 4, pp. 385-392, 2009.

4. R. B. Drude, L. A. Balart, J. P. Herrington, E. N. Beckman, and T. W. Burns, "Gastric xanthoma: Histologic similarity to signet ring cell carcinoma," Journal of Clinical Gastroenterology, vol. 4, no. 3, pp. 217221, 1982.

5. A. Alguacil-Garcia, "Artifactual changes mimicking signet ring cell carcinoma in transurethral prostatectomy specimens," The American Journal of Surgical Pathology, vol. 10, no. 11, pp. 795-800, 1986.

6. O. Khan and S. Ligato, "Identification of Signet Ring Cell Change inColonic Subserosa in the Setting ofClostridium difficile Colitis: Report of a Nonneoplastic Mimicker of Signet Ring Cell Carcinoma," International Journal of Surgical Pathology, vol. 25, no. 2, pp. 168-172, 2017.

7. G. De Petris, R. Lev, and S. Siew, "Peritumoral and nodal muciphages," The American Journal of Surgical Pathology, vol. 22, no. 5, pp. 545-549, 1998.

8. A. Trivedi and S. Ligato, "Microcystic/ Reticular schwannoma of the proximal sigmoid colon: case report with review of literature," Archives of Pathology \& Laboratory Medicine, vol. 137, no. 2, pp. 284-288, 2013.

9. O. Houghton and B. Herron, "Benign signet ring cells in the subserosa of the small intestine: a pseudoneoplastic 
phenomenon," The Ulster Medical

Journal, vol. 75, no. 1, pp. 93-94, 2006.

10. R. Vajpeyi and R. Chetty, "Starvationinduced fat atrophy in the omentum: A diagnostic pitfall," Diagnostic Histopathology, vol. 19, no. 12, pp. 457459, 2013.

11. G. P. Pena, C. K. Berenstein, and C. A. Ribeiro, "Mucophagocytizing Histiocytes in a Low-Grade Appendiceal Mucinous Neoplasm Mimicking Signet-Ring Mucosecreting Adenocarcinoma Cells," International Journal of Surgical Pathology, vol. 22, no. 3, p. 241, 2014.

12. D. N. Lortscher, E. K. Satter, and L. S. Romero, "Signet ring like cells: No longer a "signature" of glandular differentiation," Dermatology Online Journal, vol. 18, no. 4, p. 3, 2012.

13. Zhang X, Findeis-Hosey JJ. Dystrophic adipocytes mimicking metastatic signet ring cell adenocarcinoma: a diagnostic pitfall in a cachectic patient. Case reports in pathology. 2018 May 7;2018.

14. C. Bing, S. Russell, E. Becket et al., "Adipose atrophy in cancer cachexia: Morphologic and molecular analysis of adipose tissue in tumour-bearing mice," British Journal of Cancer, vol. 95, no. 8, pp. 1028-1037, 2006.

15. M. L. Batista, F. S. Henriques, R. X. Neves et al., "Cachexia associated adipose tissue morphological rearrangement in gastrointestinal cancer patients," Journal of Cachexia, Sarcopeniaand Muscle, vol. 7, no. 1, pp. 37-47, 2016.

16. M. J. Alves, R. G. Figuer^edo, F. F. Azevedo et al., "Adipose tissue fibrosis in human cancer cachexia: The role of TGF $\beta$ pathway," BMC Cancer, vol. 17, no. 1, article no. 190, 2017.
17. M. L. Batista, M. Olivan, P. S. M. Alcantara et al., "Adipose tissue-derived factors as potential biomarkers in cachectic cancer patients," Cytokine, vol. 61, no. 2, pp. 532-539, 2013. 